\title{
"FÊ-LO NO IMPULSO DE UM NOBRE CRIMME, SENÃO DE SENTIMENTO DA HONRA ULTRAJADA": A VIOLÊNCIA CONTRA A MULHER NOS AUTOS CRIMES DE FERIMENTOS LEVES DA COMARCA DE BRAGANÇA-PA (1910-1920)
}

\section{"I DID IT IN THE IMPULSE OF A NOBLE CRIME, IF NOT OF FEELING OF OUTRAGED HONOR": THE VIOLENCE AGAINST WOMEN BASED ON THE ANALYSIS OF THE AUTO CRIMES OF MINOR INJURIES OF THE DISTRICT OF BRAGANÇA-PA (1910-1920)}

Filipe de Sousa Miranda*

Resumo: $O$ presente artigo tem por objetivo construir algumas hipóteses a respeito dos possíveis contextos em que a violência perpetrada contra a mulher por um homem de seu núcleo familiar era considerada um instrumento legítimo de manutenção da autoridade masculina pela Justiça Pública da Comarca de Bragança-PA na segunda década do século XX. A metodologia perpassa a análise qualitativa de dois casos pontuais localizados no arquivo histórico do Fórum da Comarca de Bragança-PA de "Autos Crimmes de Ferimentos Leves" datados de 1912 e 1917. Em seu percurso, o texto apresenta de modo sucinto o processo de constituição da Comarca de Bragança-PA, bem como a forma como ela estava estruturada na segunda década do século XX. Em seguida, adentra o cotidiano de funcionamento do Tribunal Correcional, instância responsável pelo julgamento dos delitos de ferimentos leves. Posteriormente, volta-se para as nuances do processo de construção de uma "verdade" final sobre o ato delituoso nos processos crimes analisados, compreendo que a versão dos fatos considerada verídica pela Justiça Pública expressa discursos que denotam em que possíveis cenários a violência exercida pelo homem contra a mulher não era suscetível a punições legais.

Palavras-chave: Violência. Mulher. Gênero. Verdade. Ferimentos Leves.

Abstract: The present article aims to build some hypotheses regarding the possible contexts in which the violence perpetrated against women by a man her family nucleus was considered a legitimate instrument for maintaining male authority by the Public Justice of the District of Bragança-PA in the second decade of the $20^{\text {th }}$ century. The methodology covers the qualitative analysis of two specific cases located in the historical archive of the Bragança-PA District Court of "Autos Crimmes de Injuries" dated of 1912 and 1917. In its course, the text presents the process of constituting the District of Bragança-PA, as well as the form as it was structured in the second decade of the $20^{\text {th }}$ century. Then it goes into the daily functioning of the Correctional Court, the body responsible for judging the crimes of minor injuries. Subsequently, it turns to the

\footnotetext{
* Mestrando pelo Programa de Pós-Graduação em Ciências do Patrimônio Cultural - Universidade Federal do Pará. Graduado em História pela Universidade Federal do Pará - Campus Universitário de Bragança-PA. Membro do Grupo de Estudos e Pesquisas Interculturais Pará- Maranhão (GEIPAMUFPA) e do Grupo de Pesquisa Arte, Corpo e Conhecimento (UFPA). E-mail: filipesousamyranda@gmail.com.
} 
nuances of the process of building a final "truth" about the criminal act in the criminal proceedings analyzed, I understand that the version of facts considered true by the Public Justice expresses speeches that denote in which possible scenarios the violence exercised by man against women was not susceptible to legal punishment.

Keywords: Violence. Woman. Genre. Truth. Minor injuries. 


\section{INTRODUÇÃO}

Em 181 anos de funcionamento, a Comarca de Bragança-PA acumulou em seu acervo permanente ou arquivo histórico um universo de registros de proporções ainda desconhecidas em sua totalidade. Esse conjunto é caracterizado pela incidência de uma pluralidade de tipos documentais, produzidos ou reunidos pelo Poder Judiciário no exercício de suas atribuições. Podem ser apontados como exemplos os processos de natureza cível e criminal, escrituras de compra e venda de propriedades, correspondências trocadas entre autoridades locais, plantas de edifícios, fragmentos de jornais locais e estatutos de associações e irmandades.

Sendo composto em sua totalidade por registros findos, que já não mais detém o valor primário para o qual foram gerados, este arquivo conserva uma "função social", atuando enquanto instrumento de apoio ao exercício da cidadania, no que tange ao direito à informação e à produção do conhecimento científico. Além de configurar-se receptáculo de diversas histórias e memórias, tanto da instituição que o produziu, cuja trajetória e feições assumidas ao longo da história do Estado brasileiro se materializam nestes documentos, quanto dos diversos sujeitos que habitaram a circunscrição da comarca em diferentes temporalidades.

Este estudo é fruto do Trabalho de Conclusão de Curso intitulado "Cotidiano, Cidade e Justiça: uma análise dos processos crimes da Comarca de Bragança-PA (1910-1920)" defendido em janeiro deste ano na Faculdade de História do Campus Universitário de Bragança e orientado pela Prof. ${ }^{a}$ Me. Magda Nazaré Pereira da Costa. O TCC foi construído a partir da análise de 17 processos crimes localizados no arquivo histórico do Fórum da Comarca de Bragança-PA, que faziam referência a delitos de ferimentos leves e estavam circunscritos na temporalidade que vai do ano 1910 ao ano de 1920. Tinha por objetivo desvelar o cotidiano dos múltiplos sujeitos que se encontravam a contraluz de uma idealizada "modernidade", pensada para a cidade de Bragança no início do século XX.

Este artigo, como desdobramento do referido trabalho, busca suscitar uma reflexão e levantar algumas hipóteses a respeito dos possíveis contextos em que a violência praticada contra a mulher, por um homem de seu núcleo familiar, era considerada pela Justiça Pública da Comarca de Bragança-PA na segunda década do século XX, um instrumento legítimo de manutenção da autoridade masculina. 
Para pensar o fenômeno da violência, o presente trabalho vai ao encontro das acepções de Felipe Berté Freitas (2017). Estudando os processos crime das comarcas da região Norte do Rio Grande do Sul datados de 1900 a 1945, o autor aponta que a violência possui significados sócio-históricos que estão intimamente ligados ao cotidiano dos sujeitos que figuram nas ações. Esta vincula-se a códigos de conduta e sistemas de valores vigentes naquele contexto:

Que a violência estava conectada tanto a elementos culturais como honra masculina e familiar, vingança, virilidade, exercício de autoridade, dominação masculina e relações de gênero quanto às contradições estruturais em torno da propriedade e do poder político (FREITAS, 2017, p. 50-51).

Metodologicamente, o texto está alicerçado na análise qualitativa de dois processos crimes de ferimentos leves: os "Autos Crimmes de Ferimentos" leves em que é réu Manoel João de Lima Cavalcante e autora a Justiça Pública, datados de 1917 e os "Autos Crimmes de Ferimentos Leves" em que é autora a Justiça Pública e réu Antonio Roberto da Luz, datado de 1912 (BRAGANÇA [PA], 1912, 1917).

Esta seleção foi feita mediante a leitura integral dos 17 processos crimes de ferimentos leves localizados no arquivo histórico do Fórum da Comarca de Bragança$P A$, que remontam a segunda década do século XX. Isso implicou no estudo das declarações prestadas por 92 indivíduos: 19 réus, 17 ofendidos e 56 testemunhas de acusação. Após este processo constatou-se que deste quantitativo somente estes dois autos criminais faziam referência a casos que giravam em torno de episódios em que homens lançaram mão de atos de violência para com mulheres de seus núcleos familiares.

As narrativas produzidas pelos diversos sujeitos que emergem nestas páginas foram analisadas tendo como embasamento teórico sólidos trabalhos de autores como Sidney Chalhoub (2001), Boris Fausto (1984) e Celeste Zenha (1985), expoentes da historiografia brasileira no que diz respeito a uma História Social, que vêm demonstrando desde o final do século $X X$ o potencial das fontes judiciárias para a compreensão dos dispositivos disciplinadores e normativos que permeiam dada sociedade.

Ao longo de seu percurso o artigo atenta-se aos mecanismos por meio dos quais se produz uma "verdade" final acerca do fato que deu origem a denúncia. É preciso ressaltar, no entanto, que o intuito deste exercício não é esmiuçar as diversas narrativas que se fazem presentes nos autos em uma busca frenética pela "verdade" 
do que realmente aconteceu. Mas sim, abstrair os elementos que se articulam em suas entrelinhas, dando-Ihes sentido. Parte-se da ideia de que estes elementos podem ser indícios reveladores "de modelos culturais locais" (FARGE, 2009, p. 34). Nesta perspectiva compartilha-se dos pressupostos de Chalhoub:

[...] é possível construir explicações válidas do social exatamente a partir das versões conflitantes apresentadas por diversos agentes sociais, ou talvez, ainda mais enfaticamente, só porque existem versões ou leituras divergentes sobre as "coisas" ou "fatos" é que se torna possível ao historiador ter acesso às lutas e contradições inerentes a qualquer realidade social (CHALHOUB, 2001, p. 40).

Desenrolando-se ao longo de todo trâmite processual, a partir da confrontação das diversas versões a respeito do ocorrido, o processo de construção dessa "verdade", a ser levada em conta no ato de elaboração da sentença, legitima discursos, que por sua vez, apresentam vestígios de valores e visões de mundo que caracterizavam as práticas da Justiça Pública, poder normatizador da vida em sociedade, em uma determinada temporalidade.

\section{A CONSTITUIÇÃO DA COMARCA DE BRAGANÇA-PA}

Instituída pela lei provincial no 17, de 09 de setembro de 1839, a Comarca de Bragança-PA caracterizou-se nesse contexto como uma das maiores, em extensão, e uma das mais dinâmicas em atividade, da então Província do Pará, sustentando-se ainda como tal, posteriormente, com o advento do regime republicano e a criação do atual estado do Pará (PARÁ, 2018).

Criada a partir de uma subdivisão da então Comarca do Grão-Pará, que elevou à condição de comarca os Termos de Bragança e Turiaçu, sua jurisdição original englobava um vasto território formado pela Vila de Bragança (cabeça do termo) e freguesias de São José do Piriá, Gurupi, Vizeu, além da povoação do Turiaçu, fazendo fronteira com a antiga Província Maranhão.

Nesse contexto de vigência do Império do Brasil, a administração judiciária do Estado brasileiro era regida pelo Código de Processo Criminal de Primeira Instância, promulgado em 1832, que definia uma Comarca como:

[...] circunscripções judiciárias compreendendo um Termo ou mais, e podiam ser gerais e especiais. Eram a sede das Relações. Na Comarca haviam um Juiz de direito, e nas cidades mais habitadas poderiam haver até três juízes 
com jurisdição cumulativa, ficando a cargo de um deles a Chefia de Polícia. (PEREIRA, 1998, p. 19).

Essa estrutura administrativa estava subdividida em Termos. Esses eram unidades que reuniam um ou mais municípios, e contavam com um conselho de jurados, um juiz municipal, um promotor público, um escrivão de execuções e os oficiais de justiça. Usava-se a expressão "cabeça do termo" para fazer alusão à localidade que dentro do Termo possuía, entre outras coisas, maior densidade populacional e em consequência uma estrutura administrativa mais complexa (PEREIRA, 1998, p. 19).

Ernesto Cruz (1974, p. 39) ressalta que esse período de estabelecimento da Comarca de Bragança-PA é marcado por intensos debates por parte das autoridades provinciais, no que tange à revisão dos moldes em que o Poder Judiciário estava estruturado na Província do Pará e sua real capacidade de cumprir suas atribuições legais. No mais, tratando-se especificamente dessa região, havia a necessidade de se definir um centro de poder mais próximo da já mencionada povoação de Turiaçu, que reivindicava sua anexação à Província do Maranhão. A justificativa utilizada perpassa as dificuldades geográficas de acesso a Belém.

Em discurso proferido na abertura da Assembleia Legislativa Provincial em 15 de agosto de 1839, o presidente da Província Doutor Bernardo de Souza Franco solicita:

\footnotetext{
Podeis porem decretar a creação de mais duas ou trez Commarcas na Provincia, e eu vos requizito com particularidade a elevação dos Termos de Bragança, e Turi-assú, á Commarca.

Esta medida he da primeira necessidade para dár um centro judiciário mais poximo ao Termo de Turri-assú, e para tirar aos pouquissimos habitantes deste Districto os pretextos com que requerendo a Assembléa Geral a desmembração do seu território do da Província do Pará. (GOVERNO DA PROVÍNCIA DO PARÁ,1839, p. 6).
}

Diante da anuência da Assembleia Legislativa Provincial, um ano depois, empossa-se o primeiro juiz de direito da recém-criada Comarca de Bragança-PA, doutor Agostinho Moreira Guerra. Em 1852, a comarca perde a jurisdição sobre o território de Turiaçu, por conta da sua anexação a Província do Maranhão, mediante decreto imperial. 


\section{ESTRUTURA ADMINISTRATIVA DO PODER JUDICÁRIO PARAENSE DURANTE A PRIMEIRA REPÚBLICA}

Sendo o Poder Judiciário extremamente mutável, é óbvio que do processo de constituição da Comarca de Bragança-PA em 1839, anteriormente descrito, até a década de 1910, temporalidade na qual este trabalho está centrado, este passou por uma série de modificações e reformulações. As mais latentes estão inseridas no contexto de passagem do regime imperial para o regime republicano em 1889. A análise de cada uma delas, em suas nuances e pormenores, não faz parte da proposta deste texto. A fim de se compreender alguns elementos processuais presentes nos autos criminais analisados, buscar-se-á aqui definir, por hora, como o Poder Judiciário estava organizado no período analisado (1910-1920) e, em consequência, a própria Comarca de Bragança-PA. Pois, conforme ressalta Grinberg:

[...] para estudar processos criminais, um dos pontos de partida é justamente
conhecer a legislação em vigor no período, que nem sempre, como vimos,
está separada em diferentes corpus legislativos. Sem ela, não se entende a
lógica do andamento do processo, as sentenças proferidas, as
argumentações de advogados e as interpretações de juízes. (GRINBERG,
2009, p. 124).

Conforme elenca Silvio Hall Moura (1974), com o advento do regime republicano e a posterior promulgação da Constituição do Estado do Pará, no ano de 1891, a estrutura do Poder Judiciário paraense passou a compreender: um Tribunal Superior de Justiça, com sede na capital, Belém; juízes de direito e seus substitutos; nas Comarcas, jurados, com poder de decisão em matéria criminal e Tribunais Correcionais, cujo número era determinado em lei ordinária.

Posteriormente, pela força da Lei № 15, de 14 de janeiro de 1892, as Comarcas passaram a subdividir-se em distritos judiciários, tantos quantos fossem seus antigos Termos. Cada Distrito era composto de duas ou mais circunscrições, criando-se também, a partir de então, o cargo de juiz substituto, um para cada Comarca (MOURA, 1977).

Em 1896, a partir da Lei ํo 455, a estrutura judiciária do Estado sofre uma reformulação, sendo composta dali em diante, pelo Senado, Tribunal Misto, Tribunal Superior de Justiça, júri, Tribunais Correcionais, juízes de direito, juízes substitutos e seus suplentes (SÃO PAULO [Estado], 1896).

Em 1904, no bojo da reforma da constituição estadual, entra em vigor a Lei no 930, de 25 de outubro de 1904 (MOURA, 1977). Esta define, entre outras coisas, que 
cada distrito deveria dispor de um Tribunal Correcional. Nos Distritos que fossem sede de Comarca, esse Tribunal era formado pelo juiz de direito, juiz substituto e o primeiro suplente deste. Nos demais Distritos, tinha-se um juiz substituto e dois cidadãos sorteados dentre os jurados suplentes de Distrito.

\section{O TRIBUNAL CORRECIONAL: O RITUAL DO JULGAMENTO E A PRODUÇÃO DA VERDADE NOS PROCESSOS CRIMINAIS}

Os "Autos Crimmes de Ferimentos" leves em que é réu Manoel João de Lima Cavalcante e autora a Justiça Pública, datados de 1917 e os "Autos Crimmes de Ferimentos Leves" em que é autora a Justiça Pública e réu Antonio Roberto da Luz, datado de 1912 (BRAGANÇA [PA], 1912, 1917), foram julgados pelo Tribunal Correcional do Distrito, que era a sede da Comarca de Bragança-PA. O magistrado Almir de Lima Pereira, em seu estudo a respeito da História do Poder Judiciário no Pará, aponta como competência deste Tribunal:

Tinha a missão de julgar as infrações das posturas municipais, dos termos de bem viver e de segurança, as contravenções punidas com multa e que tivesse pena maior de um ano de prisão celular com multas ou sem elas, ameaças, injúrias, calúnias, etc. Esses tribunais tinham recursos para o Tribunal de Justiça. (PEREIRA, 1998, p. 25).

As intimações constantes nos processos, encaminhadas a réus, ofendidos e testemunhas, revelam que as audiências se davam semanalmente, às quartas-feiras, a partir das oito horas da manhã. O local designado era a sala de audiências do Paço Municipal. Em mandado emitido pelo juiz de direito da Comarca de Bragança, Doutor Manoel Maroja Netto, no processo movido pela Justiça Pública contra o réu Manoel João de Lima Cavalcante, no ano de 1917, constam tais informações:

Mando a qualquer official de Justiça neste Juízo que cumprindo este indo por mim assignado se dirija a Villa de Quaty-purú desta comarca e sendo ahi intime a Manoel Martins de Vera- Cruz, Feliciano Muniz Pinheiro e Antonio do Rozario para comparecerem a sessão do Tribunal Correcional que se reunirá no dia 19 do corrente, a fim de deporem como testemunhas no processo crimme que a Justiça Publica move contra Manoel João de Lima Cavalcante, dennunciado pelo crimme previsto no artigo 303 do Codigo Penal citando o réo para se ver processar sob pena de revelia e scientificando a todos que o Tribunal se reúne as quartas feira de todas as semanas no Paço Municipal as oito horas da manhã na sala das audiencias. Cumpra. Bragança 7 de novembro de 1917. Eu Zacharias Ribeiro Corrêa, Escrivão o escrevi.

Manoel Maroja Netto. (BRAGANÇA [PA], 1917, p. 21). 
As "Actas das Sessões do Tribunal Correcional", anexadas aos processos em forma de cópia pelo escrivão competente, revelam em seus pormenores os ritos jurídicos e sujeitos que perpassavam o cotidiano desse tribunal. De início, essas registram a presença das autoridades responsáveis pelo andamento da ação e por seu julgamento. Assim, ali estão presentes, o juiz de direito da Comarca, também presidente do Tribunal Correcional; um juiz substituto; o promotor público da Comarca ou seu adjunto, o escrivão e o oficial de Justiça (BRAGANÇA [PA], 1917).

Estando todos em seus lugares, dá-se início ao rito do julgamento. $O$ oficial de Justiça toca a campainha, e logo em seguida o presidente do tribunal declara aberta a sessão. Cabe ao escrivão fazer a leitura dos processos a serem julgados naquele dia. Normalmente, seu número não passava de três.

$\mathrm{Na}$ ordem listada, são convocados perante os julgadores as testemunhas de acusação a serem inquiridas. Essas deveriam ser no mínimo três. Ao término de seus depoimentos, tanto a promotoria quanto o réu ou seu representante legal, quando se faziam presentes, têm o direito de fazer perguntas ou contradizer os fatos narrados. Feito isso, seus depoimentos são reduzidos a termos nos autos. Ou seja, transcritos pelo escrivão, são compilados em um texto que corresponde ao "Termo de Inquirição das Testemunhas de Accuzação". Esse processo será novamente apresentado na próxima sessão, quando será declarado concluso com a expedição de seu veredito.

Todos as ações são submetidas a esse ritual, a menos que se dê alguma interrupção pontual, normalmente a ausência de alguma testemunha ou o impedimento legal de alguma autoridade. Isso pode ser observado na sessão do dia 18 de abril de 1918, quando foram conclusos os autos referentes ao processo movido pela Justiça Pública da Comarca de Bragança contra Manoel João de Lima Cavalcante. Na ocasião, estando presente o segundo suplente do juízo substituto da segunda circunscrição, este declarou não estar apto a julgar o caso, por ter servido de escrivão nos Inquéritos Policiais que originaram os autos:

\footnotetext{
Então o Meritissimo Juiz de Direito declarou aberta a sessão e eu escrivão aprezentei o processo em que é autora a Justiça Pública e reo Manoel João de Lima Cavalcante, e dados os pregões não compareceu o réo e o membro do Tribunal declarou ser impedido para julgar o processo visto ter servido de escrivão nos inquéritos policiais que serviram de base para elle pelo que o Meritissimo Prezidente adiou a sessão, digo: adiou o julgamento e mandou convocar o primeiro suplente. (BRAGANÇA [PA], 1917, p. 30).
} 
Essa justificativa faz menção a uma realidade visualizada desde os Oitocentos nas Comarcas mais afastadas da capital: a carência de cidadãos que possuam as atribuições exigidas pela legislação para ocupar determinados cargos dentro dessa instituição. Assim, a rotatividade dos mesmos sujeitos em cargos distintos, nesse caso o de escrivão na Subdelegacia de Polícia de Quatipuru e o de juiz substituto da segunda circunscrição, apresenta-se como uma alternativa a esta problemática.

Concluído o cronograma de julgamentos daquele dia, cabia ao juiz de direito, presidente do Tribunal Correcional, declarar encerrada a sessão, devendo todas as autoridades presentes registrarem sua assinatura na "Acta". Essa em seguida seria copiada pelo escrivão e anexada a cada um dos autos julgados.

Esse conjunto de ritos, protocolos e formalidades, repetidos a cada nova sessão e narrados pelo escrivão sucintamente naquele documento, possui significado nodal dentro da trama judiciária. Foucault (1979), analisa o tribunal enquanto mecanismo de poder circunscrito no aparelho do Estado capitalista e ressalta que as próprias características com que esse se apresenta perante a sociedade refletem uma ideologia de justiça: a burguesa. Nessa perspectiva, tanto aqueles que se fazem presentes no ato do julgamento, sejam as partes envolvidas no conflito ou os juízes, quanto o lugar reservado a cada um no espaço físico do tribunal, expressam essa ideologia de justiça. A disposição desses elementos busca, entre outras coisas, ressaltar a legitimidade dos julgadores para determinar, dentre tudo aquilo que for dito, o que configura "a verdade", além da idoneidade do veredito proferido, frente aos interesses particulares dos que se fazem ali presentes. A respeito disso, Foucault disserta:

[...] mas olhemos meticulosamente o que significa a disposição espacial do tribunal, a disposição das pessoas que estão em um tribunal. Isso pelo menos implica uma ideologia. Qual é essa disposição? Uma mesa; atrás dessa mesa, que os distancia ao mesmo tempo das duas partes, estão terceiros, os juízes; a posição destes indica primeiro que eles são neutros em relação a uma e a outra; segundo, implica que o seu julgamento não é determinado previamente, que vai ser estabelecido depois do inquérito pela audição das duas partes, em função de uma certa norma de verdade e de um certo número de ideias sobre o justo e o injusto; e, terceiro, que a sua decisão terá peso de autoridade. Eis o que quer dizer esta simples disposição espacial. (FOUCAULT, 1979, p. 45).

$O$ ato de estabelecimento de "uma verdade", por parte dos agentes da Justiça, encontra sua culminância na sentença proferida perante o tribunal, visto ali estar presente a única autoridade detentora do poder legal de decretar a culpabilidade ou a 
absolvição de outrem. No entanto, conforme ressalta Fausto (1984) em seu estudo clássico sobre a criminalidade na cidade de São Paulo entre os anos de 1880 a 1924, a "verdade" eleita pelo veredito do juiz é fruto de uma construção que se desenrola ao longo dos elementos que constituem o processo penal.

De acordo com o autor (FAUSTO, 1984), esse processo penal, ou esse conjunto de "autos criminais", fazendo uso da expressão constante na própria documentação analisada, configuram um "produto artesanal", construído gradativamente a partir da junção de uma série de peças. Essas peças são os diversos "autos" que vão agregando elementos à narrativa judiciária. Normalmente figuram nos autos criminais de ferimentos leves: "Autos de Exame de Corpo de Delicto", "Autos de Exame de Sanidade", "Autos de Declaração do Paciente", "Autos de Qualificação do Réu", "Autos de Declaração do Acusado", "Autos de Inquirição das Testemunhas de Accuzação", dentre outros. Esses documentos fazem alusão, para Fausto, a dois acontecimentos distintos.

Primeiramente, ao ato que infringe a norma penal, nos casos aqui analisados, uma agressão deflagrada contra outrem, sem necessariamente haver derramamento de sangue, conforme dispõe o art. 303 do Código Penal de 1890 (BRASIL, 1890). Em segundo, aquele que se desenrola a partir do momento em que, detectada a quebra da ordem social, os mecanismos repressores do Poder Judiciário são ativados. É nesse segundo momento que se inicia a tentativa de reconstituição do ato infracional, a fim de se definir um "princípio de verdade" que indique culpabilidade ou inocência:

\footnotetext{
Na sua materialidade, o processo penal, como documento diz respeito a dois "acontecimentos" diversos: aquele que produziu a quebra da norma legal e um outro que se instaura a partir da atuação do aparelho repressivo. Este último tem como móvel aparente reconstituir um acontecimento originário, com o objetivo de estabelecer a "verdade" da qual resultará a punição ou a absolvição de alguém. (FAUSTO, 1984, p. 21).
}

Complexo e meticuloso, esse processo inicia-se ainda na delegacia ou subdelegacia de polícia, com a constituição do Inquérito Policial ou a formação do "Summário de Culpa". Nesse momento, réu, ofendido, testemunhas e peritos são convocados perante a autoridade policial e ouvidos pela primeira vez. Após prestar o compromisso legal, seu papel é o de "dizer a verdade do que soubessem e thes fosse perguntado". Este trâmite tem por objetivo reunir elementos que comprovem a materialidade do delito, matéria-prima dos autos criminais. Marluce Dias Fagundes descreve esse processo: 


\begin{abstract}
O inquérito policial, sobretudo, constitui uma das modalidades de apuração preliminar das infrações penais. Sendo todo o procedimento legal destinado à reunião de elementos acerca de uma infração penal, tendo o caráter extrajudicial. Os elementos da instrução policial são autuados em conjunto, daí chamarem-se autos de inquérito. Neles tem origem os fundamentos da prova, como exames periciais, autos de apreensão, de reconhecimento e de reconstituição, depoimentos e acareações, identificação e levantamento da vida pregressa do indiciado, etc. $O$ inquérito policial é encerrado com o relatório do delegado, onde o mesmo expõe de forma neutra uma síntese do ocorrido. (FAGUNDES, 2017, p. 241).
\end{abstract}

Nesse ínterim, observa-se na leitura dos autos o florescer não de uma, mas de várias "verdades". Réu, ofendido e testemunhas narram o mesmo fato, sob pontos de vista distintos, dando origem a uma gama de versões sobre o que realmente teria se sucedido. Cada depoimento, em sua reconstrução do ato delituoso, passa a ser permeado de uma série de elementos que objetivam convencer aquele que ouve do que se fala, ressaltando um princípio de culpabilidade ou inocência.

As verdades individuais, expressas nos depoimentos de acusados, vítimas, testemunhas, peritos e autoridades, se atritam e complementam, no ritual de estabelecimento da verdade jurídica definitiva, que dará origem à sentença final. Esta "verdade final", produto do processo criminal, é denominada por Celeste Zenha, como Fábula:

A Fábula é a verdade final produzida no processo. Nada mais é do que uma historieta, tida como coerente e verdadeira, resultante do conjunto de versões apresentadas por todos aqueles que falaram durante o processo: queixoso, autoridade, ofendido, peritos, testemunhas. Ela se distingue da ação, perdida no tempo, que serve de pretexto para o denunciante. Analisando os autos dos processos verificamos que um cadáver pode ser motivo suficiente para que seja instaurado um inquérito para averiguação de um assassinato. Mas o que realmente aconteceu entre o denunciado e o morto ficou perdido no tempo. Logo, um discurso expresso no processo penal fala a respeito de um fato, e ao contrário de revelar, produz uma verdade responsável pela condenação ou absolvição do réu. As práticas jurídicas produzem, portanto, uma verdade dos autos e jamais a repetição (repetida ação) do fato acontecido no passado, da agressão que ocasionou a morte. $O$ que nos permite concluir que o ocorrido se transforma em crime, através da verdade produzida nos autos. (ZENHA, 1985, p. 126).

A construção das "verdades" a que se tem acesso a partir dos testemunhos arrolados nos autos resguarda uma série de pormenores, que influenciam diretamente o trabalho metodológico para com essas fontes. Conforme ressalta Ginzburg (1991), no esclarecedor artigo em que traça analogias entre as figuras do inquisidor e do antropólogo, ao recorrer a fontes documentais escritas para o estudo de sociedades não contemporâneas, deparamo-nos frequentemente com documentos redigidos a 
partir de relatos orais. Tratando-se de fontes judiciárias, essa realidade se torna ainda mais latente.

O processo de conversão daquilo que é falado para o que efetivamente é registrado nas páginas do processo criminal está sujeito, na cena judiciária, a distorções. Essas são resultantes da intervenção de uma série de sujeitos, dentre os quais se destacam as autoridades policiais e judiciárias: agentes policiais, delegados, subdelegados, prefeito de segurança, promotores, escrivães e juízes. Nessa ótica, esses indivíduos, no exercício de suas atribuições e na autoridade que estas the conferem, influem diretamente no ritual de produção das "verdades" visualizadas em cada depoimento. Fazendo uso da metáfora proposta por Ginzburg (1991), é por "sob seus ombros" que se observam réus, ofendidos e testemunhas tecerem suas narrativas, e construírem sua verdade a respeito do fato que originara o delito. Para o referido autor, registros desta natureza:

[...] devem ser lidos como o produto de uma inter-relação peculiar, claramente desequilibrada. No sentido de decifrá-los, devemos aprender a captar, por baixo da superfície uniforme do texto, uma interação sutil de ameaças e temores, de ataques e recuos. Devemos aprender a desenredar os diferentes fios que forma o tecido factual destes diálogos. (GINZBURG, 1991 p. 15).

\section{A VIOLÊNCIA CONTRA A MULHER A PARTIR DE DOIS AUTOS CRIMES DE FERIMENTOS LEVES (1912-1917)}

Discutido anteriormente, o complexo processo de construção de uma "verdade" a respeito do fato que origina a ação criminal se dá mediante a intervenção de autoridades policiais e judiciárias e da confrontação de narrativas distintas a respeito do ocorrido. $\mathrm{Na}$ elaboração destas narrativas, os indivíduos inquiridos se valem da articulação de uma série de elementos advindos do contexto histórico e social em que estão inseridos e que são empregados na tentativa de conferir maior veracidade a sua versão do ocorrido. Convencendo, deste modo, as autoridades. Estes elementos fornecem importantes vestígios para a construção do saber historiográfico (FARGE, 2009, p. 39).

Partindo desse pressuposto, propõe-se a análise dos depoimentos do acusado, Manoel João de Lima Cavalcante, lavrador, casado, de 25 anos de idade, e da ofendida, Ângela Maria Francisca da Silva, lavradora, solteira, de 35 anos de idade fornecem importante vestígios. Esses foram proferidos na Subdelegacia de Polícia da 
Vila de Quatipuru', no ano de 1917. Manoel era acusado de, na tarde do dia 27 de setembro daquele ano, por volta das 17 horas, ter ferido sua sogra, Ângela, com uma faca, após chegar de viagem embriagado. De acordo com a vítima, nos "Autos de Declaração da Paciente", os fatos se desenrolaram da seguinte forma:

[...]declarou a paciente que hontem as trez horas da tarde mais ou menos chegando ella declarante do sitio para onde se achava encontrou sua filha de nome Maria casada com Manoel João de Lima Cavalcante chorando a interrogou o que ella tinha, disse que seu marido lhe tinha dado muito pancada, ella como mãe chamou o seu genro e o advertiu-lhe pedindo que não fizesse mais isso, porém nada atendeu, e ella declarante viu-se obrigada a levar o facto ao conhecimento da Policia o qual o cabo do destacamento o chamou e pediu que não fizesse mais isso, deu-lhe bons conselhos, promettendo não fazer mais tal couza e que dessa data viveria em paz tanto com a sogra como com a mulher; e quando mais tarde as cinco horas mais ou menos, estando ella declarante assentada em um banco sem dar fé o que elle fazia elle agarrou pelo pescoço e deu-lhe uma facada com um punhal abaixo um pouco da pá prostando-a no chão, ella declarante gritou que accudissem e elle Manoel João de Lima Cavalcante correu atraz da mulher delle para mattar, porem não a agarrou entrando ella na caza vizinha ahi apareceram diversas pessôas que o accusaram e elle fugiu porem foi pegado as seis e meia horas da tarde e recolhido a prisão. (BRAGANÇA [PA], 1917, p. $5-5 v)$.

Em seu depoimento, Manoel apresenta os acontecimentos transcorridos aquela tarde da seguinte maneira:

[...]disse que hoje as cinco horas da tarde estando um pouco embriagado, tendo chegado de uma viagem que tinha feito e ao entrar em sua casa sua sogra Angela Maria Francisca da silva e sua mulher Maria Clementina da Silva puzeram-se a dizer-lhe indiretas aborrecendo-se com isso em primeiro lugar repellio sua mulher e sua sogra tomando parte na ocasião, elle como disse um pouco embriagado armou-se de uma faca e deu-lhe uma facada, commettendo o crime. (BRAGANÇA [PA], 1917, p. 4).

Na narrativa apresentada por Ângela Maria, há a preocupação de ressaltar, a partir de fatos que antecederam o delito, o histórico de agressividade e perversidade do réu. Para isso, são evocadas supostas agressões impetradas por esse contra sua filha. Agressões essas que inclusive exigiram a intervenção de uma autoridade policial. Manoel Cavalcante, em sua fala, busca por outro lado apresentar-se como o homem que volta ao seu lar depois de uma viagem, mas não encontra neste ambiente, paz e tranquilidade. Pelo contrário, assim que retorna é bombardeado por indiretas provenientes de sua esposa e sogra, o que justificariam seu aborrecimento. Há ainda

\footnotetext{
${ }^{1}$ Tendo sua ocupação datada do período colonial, Quatipuru foi desmembrada do município de Bragança e elevada definitivamente a categoria de vila no ano de 1902, a partir da Lei Estadual no 832, tendo como sede a povoação de Quatipuru. Desde 1994, por conta de Lei Estadual no 5859 de 1994 (PARÁ [Estado], 1994), foi elevada à categoria de município, localizando-se a aproximadamente 101 $\mathrm{Km}$ do município de Bragança-PA. (IBGE, 2017).
} 
a preocupação de ressaltar que em um primeiro momento, tentou afastar a esposa. Porém, diante da intervenção da sogra em um assunto que deveria ser privado, a agressão fora deflagrada. Mais tarde, nos “Autos de Perguntas”, procedidos no dia 29 de setembro de 1919, Manoel declara que: "sem semelhante tenção não tinha de cometer tal crimme não sabe como estava e o que deu-lhe para tal". (BRAGANÇA [PA], 1917, p. 11v).

Em ambas as versões, a prática do ato delituoso não é negada. No entanto, o contexto de sua realização, dependendo de quem fala, é revestido de elementos distintos, que buscarão ressaltar a periculosidade do réu, ou justificar sua atitude. Contrastam-se neste ínterim, duas verdades distintas, a da ofendida e do réu. A partir dessas, os demais elementos processuais serão produzidos, na tentativa de agrupar provas que corroborem com uma delas, ou, quem sabe, apresentem nova versão para o fato.

Nesse caso em específico, os relatos das testemunhas arroladas serão capitais nesse processo. Manuel Martins de Vera Cruz, lavrador, de 66 anos de idade, viúvo, não sabendo ler nem escrever afirma que Manuel:

\begin{abstract}
Vivia em constante desharmonia com a mulher e a sogra Angella Maria Francisca da Silva; que no dia em que se deu o facto narrado na dennuncia deste muito cedo começou elle a ter serias discussões em caza e a uma hora da tarde mais ou menos foi a rezidencia do depoente e alhi pediu emprestada uma espingarda com a qual dizia pretender atirar nos porcos que costumavam ir numa roça de sua sogra que fica perto de sua caza; que no instante sabendo de sciencia própria que referida roça não havia mais couza alguma a aproveitar porque há mais de um mez havia tudo sido destruído pelos porcos, julgou que o dennunciado pediu a espingarda com intuito de matar sua mulher ou sua sogra, recuzando-se por esse motivo em attender ao pedido feito pelo dennunciado perante quem desculpou-se dizendo que não tinha pólvora nem chummbo e nem espoletas, ao que o mesmo respondeu que tudo isso seria por elle adquirido em caza de José Balbino logo que estivesse de posse de espingarda que apezar disso não desse a espingarda ao accuzado, que vendo o cinturão do depoente em um canto da caza tirou-o do lugar onde estava levando -o consigo que mais tarde, pelas cinco e meia indo a caza de Miguel Moreira ahi ouviu um filho menor deste referir que o dennunciado tinha ordenado a sua mulher que armasse a sua bagagem porque tencionava ir-se embora pelo que dirigiu-se para a caza do dennunciado indo procurar o cinturão; que ao chegar em caza do dennunciado antes de explicar o motivo de sua presença ali vio o dennunciado repentinamente agredir a própria sogra dando-lhe uma facada. (BRAGANÇA [PA], 1917, p. 24v-25).
\end{abstract}

Outra testemunha, Feliciano Muniz Pinheiro, de 25 anos de idade, lavrador, solteiro, não sabendo ler nem escrever, ressalta ter visto o réu arrastando sua esposa para dentro de casa. Antônio Manoel do Rozário, lavrador, de 40 anos idade, não sabendo ler nem escrever, narra que após o esfaqueamento, Maria Clementina da 
Silva correu para a casa do depoente, fugindo do marido que a perseguia com uma faca, a fim de matá-la (BRAGANÇA [PA], 1917).

É perceptível que todos esses relatos se aproximam da versão dos fatos apresentados por Ângela Maria, trazendo também à tona supostas características de Manuel, por ela elencadas, como sua agressividade e brutalidade. Proferidos no tribunal, esses forneceram aos julgadores os elementos que deveriam ser levados em conta para a construção da verdade jurídica definitiva, que serviria de base para a sentença final.

Destarte, em $1^{\circ}$ de maio de 1918, Manoel Cavalcante é condenado no grau submédio do art. 303, do Código Penal republicano de 1890. Somam-se os incursos das circunstâncias agravantes previstas no $\S^{\circ}$ do art. 39, que prevê a superioridade em armas e força do condenado. Sua tentativa de justificar a atitude delituosa, mediante a perturbação gerada por sua mulher e sogra, não é levada em conta, visto não ser evocada qualquer uma das circunstâncias atenuantes previstas pelo código (BRASIL, 1890).

Se, no caso analisado até aqui, o processo de construção da "verdade" final que embasou o veredito dos julgadores culminou na validação da versão apresentada pela vítima, Ângela Maria, levando, desse modo, a condenação de seu agressor, visto que o uso da violência de sua parte não foi considerado legítimo pelas autoridades, isso não representa uma constante. Junto aos "Autos Crimes de Ferimentos Leves" analisados, também é possível encontrar casos em que a gestação da fábula fazendo uso da expressão de Zenha (1985) - atua em um movimento bastante interessante, o de conversão da vítima em réu.

Essa perspectiva pode ser visualizada no processo crime em que Martha Francisca de Moraes figura como ofendida. O réu na ação é seu esposo, Antônio Roberto da Luz, lavrador, de 44 anos de idade, não sabendo ler nem escrever, conhecido como "Betinho". Esse era acusado de, às sete horas da manhã do dia 03 de novembro de 1912, um domingo, ter espancado, com um cacete, Martha, que se encontrava em período de gestação (BRAGANÇA [PA], 1912).

Logo no início da declaração prestada, perante o subprefeito de polícia, em 11 de novembro de 1912, Martha afirma ser solteira. Há aí uma nítida negação a sua permanência em um casamento, que, de acordo com ela, mesmo tendo se estendido 
por dezenove anos e gerado oito filhos, sempre fora marcado pela violência de seu antigo esposo (BRAGANÇA [PA], 1912). Assim, apresenta os fatos:

\begin{abstract}
E no mesmo dia, mez, anno e lugar retro declarados presente o Subprefeito de Policia cidadão Francisco Pereira da Silva, commigo escrivão abaixo nommeado, compareceu a paciente Martha Francisca de Moraes, de trinta e seis annos de idade, solteira, filha legitima de Domingos Antonio de Moraes, natural deste municipio, lavradora, não sabendo ler nem escrever; a qual declarou que no dia trez do corrente, domingo, por volta das sete horas da manhã, o seu companheiro de casa Antonio Roberto da Luz, conhecido também pelo nome de Betinho, a insultou bastante com nomes injuriosos e por fim lançando mão de um pau com esta arma lhe fez as contusões que se vê; que a declarante acha-se em estado adiantado da gravidez, tendo o seu companheiro depois deste espancamento a enxotado para fora de sua casa, indo a declarante para a de sua mãe que fica não fica muito longe da sua; que conta oito filhos tido com esse homem com quem cazou-se religiosamente e com quem viveu dezenove annos intimamente, sendo sempre por elle maltratada, até que desta vez em face das pancadas recebidas, resolveu vir queixar-se, mesmo porque elle seu marido ameaçou de tomar os seus filhos (BRAGANÇA [PA], 1912, p. 7).
\end{abstract}

Ao longo dos autos, revela-se na fala do réu e das testemunhas arroladas (todas do gênero masculino, é importante ressaltar), que Martha não correspondia aos padrões sociais de gênero do período. Antes do ocorrido, essa havia se evadido de sua casa, deixando a companhia de seu esposo e filhos por quase três meses, retornando já em estado adiantado de gestação. Além disso, quando estava junto a sua família, era acusada de deixar a desejar em suas funções domésticas, sendo sua má conduta objeto de comentários na vizinhança. Ao contrário de seu marido, que era considerado homem trabalhador e sério (BRAGANÇA [PA], 1912). Francisco Martins de Andrade, lavrador, casado, de 43 anos de idade, afirma:

[...] que conhece o dennunciado desde muito tempo sabendo sempre ser um homem serio e trabalhador; que entretanto não pode dizer em relação a mulher do denunciado, cuja conducta é tida como má, falando-se de sua domesticidade, até nas festas e tavernas (BRAGANÇA [PA], 1912, p. 38).

Deparamo-nos nesse processo com uma mulher que foge às convenções de uma sociedade, cujos discursos que pregavam a subserviência feminina em relação à figura masculina eram amplamente aceitos e difundidos. Sentindo-se maltratada por seu cônjuge, Martha demonstra possuir independência e autonomia suficiente para deixá-lo, mesmo após um casamento de dezenove anos que the dera oito filhos. Não é possível saber se seu retorno foi consequência dos laços afetivos mantidos para com os filhos ou do avançado estado de gravidez em que se encontrava. Porém, é perceptível que no momento em que se sentiu novamente agredida e violada por 
Antônio Roberto da Luz, prontamente lançou mão dos mecanismos que entendeu estarem a sua disposição para coibi-lo, no caso, a Justiça Pública.

A necessidade de ressaltar que eram casados religiosamente e que, apesar de sofrer agressões constantes, esteve ao lado de seu companheiro por quase duas décadas, demonstra a sensibilidade por parte da ofendida, de que para que esses mecanismos legais estivessem a seu favor e sua empreitada fosse exitosa, deveria passar a imagem desta mulher idônea e comprometida. Fausto (1984) afirma que, nesse contexto, o casamento, e em consequência, a capacidade advinda deste de gerar filhos legítimos, está intimamente ligada à noção de honra, permitindo "alcançar em parte, benefícios materiais ou ideais. Entre os benefícios, alguns correspondem não só a à autoestima como à estima das classes superiores" (FAUSTO, 1984, p. 220).

Observa-se nestes "Autos Crimes de Ferimentos Leves" um processo de construção de arquétipos a respeito de papéis sociais de gênero, semelhantes àqueles apontados pelo referido autor, nos processos crimes que envolvem delitos sexuais. Betinho compreendia que, para que não acabasse condenado, como o foi Manoel João de Lima Cavalcante, precisava justificar sua atitude, mostrando que esta não fora ocasionada por motivos frívolos. Nesta lógica, o argumento escolhido fora a defesa da honra ultrajada pelo abandono da esposa. Assim discorre em sua defesa oral:

[...] que é certo ter produzido na sua mulher as offensas physicas que tracta o processo, mas o fez em defesa de sua honra que considerava ultrajada, pelo facto de ter a sua mulher depois de ter se ausentado por quase trez mezes incompletos voltado à casa em estado de gravidez, facto esse ocorrido em dia vinte e oito de Agosto (BRAGANÇA [PA], 1912, p. 12).

No processo de construção da verdade nesta ação penal, os testemunhos proferidos em juízo corroboraram com o réu. Conforme visto anteriormente, esses foram unânimes em ressaltar sua seriedade e comprometimento para com o trabalho, virtudes muito valorizadas neste ritual de construção de uma imagem positiva. Em detrimento de Martha, que por seus atos fora apresentada como aquela que possuía conduta "má e reprovável". Afinal, como uma esposa e uma mãe era capaz de abandonar seu próprio lar?

Desse modo, nas malhas de um poder, na qual a autoridade estava concentrada nas mãos de homens - agentes policiais, oficiais de justiça, subprefeito, escrivão e Juízes - nota-se a manutenção de uma visão masculina, fortemente 
arraigada nessa sociedade. Visão essa que não enxergava com bons olhos a autonomia e independência de mulheres como Martha. A respeito disso, Fausto define algo bastante pertinente, a partir dos processos penais que fazem menção a crimes sexuais que analisou:

\begin{abstract}
Esta visão não se limita ao fato em si mesmo relevante de que o aparelho repressivo e o corpo de jurados sejam constituídos por homens, a quem cabe investigar e julgar delitos praticados por agentes do sexo masculino cujas vítimas são, em sua imensa maioria, mulheres. Diante das autoridades e das pessoas investidas de poder de julgar apresenta-se uma relação psicobiológica caracterizada como delito em determinadas circunstâncias que se liga diretamente a concepções e identidades sociais (FAUSTO, 1984, p. 185).
\end{abstract}

Indo ao encontro desta assertiva, o Tribunal Correcional, na pessoa do juiz de direito da Comarca de Bragança, Doutor Manoel Maroja Netto, opta em 12 de março de 1913 pela absolvição do réu:

\begin{abstract}
Vistos os autos, relatados e discutidos. Accordam, em conferencia, absolver o réo Antonio Roberto da Luz da accusação que Ihe intentada, condennando a fazenda estadual nas custas; por quanto se é certo que o mesmo réo praticou o crime descripto no auto de corpo de delicto de folhas, das provas dos autos se infere que fe-lo no impulso de um nobre crimme, senão de sentimento da honra ultrajada, diante do procedimento irregular e deshonesto da paciente, que, casa religiosamente e relacionando matrimonialmente com elle, há 19 annos abandona-o, para mais tarde, voltou ao antigo lar em estado de gravidez, o que nota realmente comprometer-lhe o estado, perturbandoIhe a razão, resultando d'ahi" a seu favor o $\S 4^{\circ}$ do art. 27 do codigo penal (BRAGANÇA [PA], 1912, p. 24).
\end{abstract}

O mencionado $\S^{4^{\circ}}$ do artigo 27 do Código Penal de 1890 define que não são criminosos os indivíduos que se encontrarem em estado de privação dos sentidos e de sua capacidade de discernimento no momento do crime (BRASIL, 1890). Manoel João de Lima Cavalcante, agressor de Ângela, tentou fazer uso de argumento semelhante ao declarar que, se não fossem as indiretas advindas de sua esposa e sogra que the perturbaram profundamente, jamais teria sido capaz de praticar o ato delituoso (BRAGANÇA [PA], 1917). No entanto, no caso de Antônio Roberto da Luz, as testemunhas atuaram em um processo completamente inverso ao observado no julgamento de Manoel Cavalcante. Suas falas reforçaram a imagem de Betinho enquanto um bom homem e bom marido, adequando-o ao padrão dominante de "civilidade" ao adjetivá-lo como "sério" e "trabalhador" (BRAGANÇA [PA], 1912).

O passado de violência, apontado no depoimento de Martha, se existiu foi deixado de lado, fazendo com que aquela que no início do processo penal figurava 
como vítima se convertesse ao longo dos trâmites jurídicos em ré. Exposta como uma mulher infiel de conduta duvidosa, o ato de violência de um "homem de bem" é legitimado como um mecanismo acionado para a defesa da honra ultrajada. Quanto a isto, Chalhoub disserta:

\begin{abstract}
É absolutamente necessário enfatizar este fato de que a violência do homem surge, nos casos estudados, antes como uma demonstração de fraqueza e impotência do que como uma demonstração de força, de poder. Este ponto é essencial porque o discurso dos agentes jurídicos da época tentará inverter radicalmente o significado desta violência masculina. Nestes casos em que o homem acusa a companheira de infiel, os advogados argumentarão invariavelmente que o homem partiu para a agressão porque teve sua "honra ultrajada", o que fez com que ele perdesse a noção de seus atos. Nota-se, então que 0 ato violento do macho assumiu aqui uma conotação completamente distinta: a agressão do homem passa a ser o exercício, a prática de um poder que ele tinha sobre a mulher. A "defesa da honra", portanto, transforma um ato de fraqueza e impotência em demonstração de poder e dominação. A realidade concreta dentro da qual se desenrolam as relações de amor entre esses homens e mulheres pobres é então desfigurada e distorcida para servir à ideologia da dominação masculina (CHALHOUB, 2001, p. 216).
\end{abstract}

Nesta ótica, a agressão intentada contra Martha por seu esposo, ato que dera origem ao processo criminal, e outras que eventualmente possam ter existido no cotidiano de sua vida a dois, podem ser compreendidas antes como um recurso utilizado pelo réu para estabelecer um controle sobre a esposa, que na prática não a detinha. Em sua autonomia e independência, esta lavradora da povoação Rio Bacury, assim como tantas outras mulheres das camadas populares de Bragança, foge aos estereótipos de mulher submissa e subserviente. Quando achou pertinente, foi capaz de deixar, mesmo que temporariamente, um casamento que considerava violento, e quando novamente sentiu-se agredida, recorreu a assistência da Justiça Pública, que pensou poder auxiliá-la. No entanto, sendo esse dirigido por homens, em uma sociedade patriarcal, suas características foram apontadas como deficiências e defeitos que justificariam o uso da violência.

\title{
4 CONCLUSÃO
}

O exercício analítico delineado a partir dos dois "Autos Crimes de Ferimentos Leves" que trouxeram à tona as figuras de Manoel João de Lima Cavalcante, Ângela Maria Francisca da Silva, Martha Francisca de Moraes e Antônio Roberto da Luz, apresenta as nuances por meio das quais foram gestadas as "verdades" finais a respeito dos possíveis atos delituosos que deram origem às ações penais. Base para 
a elaboração de uma sentença, que pode absolver ou condenar, esta verdade é plasmada a partir do embate de diversas versões e pontos de vista a respeito do ocorrido, e da intervenção de uma série de sujeitos, como testemunhas, escrivães, oficiais de justiça e juízes.

Esta versão dos fatos eleita como "verdadeira", valida discursos que fornecem pistas para a compreensão das concepções e valores sustentados pela Justiça Pública em determinado contexto.

Os casos elencados neste estudo, por representarem um número reduzido para uma temporalidade ampla, não podem fornecer certezas. Porém, abrem precedentes para se formular hipóteses a respeito dos possíveis cenários em que a violência perpetrada por homens contra mulheres de seu núcleo familiar era considerada legítima pelos julgadores do Tribunal Correcional da Comarca de Bragança-PA, na segunda década do século XX. Atentando-se ao fato de que a violência precisa ser entendida enquanto fenômeno que possuía significados sóciohistóricos específicos naquele contexto.

Ângela Maria Francisca da Silva foi considerada vítima ao se comprovar, mediante relato de membros de seu convívio social, a personalidade violenta e perigosa de seu genro, manifestada em outros supostos episódios de agressividade. Em nenhum momento são mencionados elementos que possam indicar um "desvio de conduta". Em detrimento, a agressão intentada contra Martha Francisca de Moraes é aceitável pois, comprovado pelas testemunhas o quanto deixava a desejar em sua "domesticidade", a violência converte-se em mecanismo lícito de reparação da autoridade que o marido na plena vivência da sua masculinidade deveria exercer sobre a esposa (BRAGANÇA [PA], 1912, 1917).

Destarte, a primeira hipótese formulada consiste na ideia de que quando o processo de constituição da "Fábula" (ZENHA, 1985) da ação penal caminha para a ratificação de uma versão dos fatos, na qual a vítima destoa dos padrões comportamentais esperados para o gênero feminino, a violência levada a cabo pelo homem é vista como um instrumento legítimo de correção da conduta desviante e manutenção de sua honra. Não sendo, nesta acepção, passível de punições legais. No entanto, quando nenhuma "transgressão" desta mulher figura no processo essa violência é legalmente penalizada. 
Intimamente imbricado à vida em sociedade, o Poder Judiciário (gerido nesse contexto exclusivamente por homens) ratifica e normatiza práticas, condutas e comportamentos considerados legalmente aceitáveis naquele tempo. Nos casos estudados, os padrões de conduta que caberiam ao homem e a mulher no exercício cotidiano de seus papéis sociais de gênero.

A segunda hipótese problematiza o reduzido número de casos desta natureza encaminhados à Justiça Pública da Comarca de Bragança entre os anos de 1910 e 1920. É possível que enxergando com desconfiança um poder gerido por homens, em uma sociedade baseada em princípios patriarcais, muitas mulheres que, como Ângela Maria Francisca da Silva e Martha Francisca de Moraes, sofreram agressões semelhantes não se sentiram confiantes para recorrer ao Judiciário. Visto que a possibilidade de serem convertidas em "rés" por conta de suas atitudes era latente.

Os caminhos para a comprovação ou refutação destas hipóteses perpassam o cruzamento com outras fontes documentais, como por exemplo os Livros de Registros de Sentença datados deste período. Assim como a sensibilidade para o fato de que os 17 autos criminais de ferimentos leves, localizados no arquivo histórico do Fórum da Comarca de Bragança-PA, são frutos de uma "seleção prévia" levada a cabo pelas condições de armazenamento inadequadas a que foram submetidos por décadas, e que possivelmente implicaram na perda de alguns exemplares deste conjunto documental.

Ressalta-se que a construção do saber historiográfico a partir das informações contidas nos processos criminais é extremamente enriquecedora e frutífera. Pois, possibilita ao pesquisador desnudar determinadas dimensões da vida em sociedade, que vão dos valores sobre os quais estava assentada, aos sujeitos, que como Martha Francisca de Moraes, iam de encontro a eles em suas vivências cotidianas.

No entanto, é necessário atentar-se sempre ao fato de que as falas registradas nas páginas são construções, forjadas em um cenário de conflitos e disputas e mediante a atuação de uma série de autoridades que mediam o processo de conversão do falado no escrito.

Paralelamente, também foi possível transitar pelo processo de constituição da Comarca de Bragança-PA, uma das mais antigas do estado do Pará, à medida em que se visualizava, a partir desta, as diversas configurações assumidas pela Justiça Pública ao longo de sua atuação. Trazendo para o centro da discussão uma das 
instâncias julgadoras de maior notoriedade do período estudado, o Tribunal Correcional.

Destarte, esta é apenas uma faceta analítica, dentre tantas outras possíveis, que esta rica documentação oferece. Sendo o Arquivo Histórico do Fórum da Comarca de Bragança-PA de tão vasta dimensão, o que foi proposto neste estudo é apenas uma ínfima parte do que estes registros podem oferecer a sociedade.

\section{REFERÊNCIAS}

BRAGANÇA (PA). Comarca de Bragança. Autos Crimmes de Ferimentos Leves em que é réu Antonio Roberto da Luz. Bragança, 1912. Digitalizado. Autos findos digitalizados e disponibilizados para pesquisa pelo Arquivo Histórico do Fórum da Comarca de Bragança-PA.

BRAGANÇA (PA). Comarca de Bragança. Autos Crimmes de Ferimentos Leves em que é réu Manoel João de Lima Cavalcante. Bragança, 1917. Digitalizado. Autos findos digitalizados e disponibilizados para pesquisa pelo Arquivo Histórico do Fórum da Comarca de Bragança-PA.

BRASIL. Decreto no 847, de 11 de outubro de 1890. Promulga o Codigo Penal. Rio de Janeiro, RJ: Presidência da República, 1890.

CHALHOUB, Sidney. Trabalho, lar e botequim: o cotidiano dos trabalhadores no Rio de Janeiro da Belle Époque. Campinhas: Editora da UNICAMP, 2001.

CRUZ, Ernesto. O poder judiciário do Pará: três períodos políticos. v.1 . Belém: Edição do Governo do Estado do Pará, 1974.

FAGUNDES, Marluce Dias. "Crimes contra os costumes" - Porto Alegre (19481964). In: VON MÜHLEN, Caroline; VENDRAME, Maíra Ines; AL-ALAM, Caiuá Cardoso (org.). Criminalidade, violência e justiça: reflexões e novas possibilidades. São Leopoldo: Oikos, 2017. E-book.

FARGE, Arlette. O sabor do arquivo. Edusp, 2009.

FAUSTO, Boris. Crime e cotidiano: a criminalidade em São Paulo (1880 - 1924). São Paulo: Brasiliense, 1984.

FOUCAULT, Michel. Microfísica do poder. Rio de Janeiro: Graal, 1979.

FREITAS, Felipe Berté. Significados sócio-históricos da violência no espaço rural sul-brasileiro: um estudo dos processos-crime das comarcas da região Norte do Rio Grande do Sul (1900-1945). In: VON MÜHLEN, Caroline; VENDRAME, Maíra Ines; AL-ALAM, Caiuá Cardoso (org.). Criminalidade, violência e justiça: reflexões e novas possibilidades. São Leopoldo: Oikos, 2017. E-book. 
GINZBURG, Carlo. "O Inquisidor como antropólogo". Revista Brasileira de História, São Paulo, v. 1, n. 21, p. 9-20, set. 1990/fev. 1991.

GOVERNO DA PROVÍNCIA DO PARÁ. Discurso recitado pelo Excํ․ Snr. Doutor Bernardo de Souza Franco, Presidente da Província do Pará, quando abriu a Assembleia Legislativa Provincial, no dia 15 de agosto de 1839. Pará: Typographia Restaurada de Santos \& menor, 1839.

IBGE. IBGE Cidades: Quatipuru [online]. 2017.

Disponível em: https://cidades.ibge.gov.br/brasil/pa/quatipuru/historico. Acesso em: 26 jun. 2020.

MOURA, Silvio Hall. Elementos para a magistratura paraense. Belém: Universidade Federal do Pará, 1974.

MOURA, Silvio Hall. Elementos para a magistratura paraense. Belém: Universidade Federal do Pará, 1977.

PARÁ (Estado). Lei n 5.859, de 05 de outubro de 1994. Cria o Município de Quatipuru e dá outras providências. Diário Oficial do Estado do Pará, Pará, 7 de setembro de 1994. Disponível em:

http://www.pge.pa.gov.br/sites/default/files/lo5859.pdf.

PARÁ (Estado). Secretaria de Estado de Turismo do Pará. Inventário da oferta Turística do Município de Bragança - PA. Belém, 2018.

PEREIRA, Almir de Lima. A História do Poder Judiciário do Pará. Belém: Tribunal de Justiça do Estado do Pará, 1998.

SÃO PAULO (Estado). Lei n.․ 455, de 26 novembro de 1896. Auctoriza o Governo o mandar abrir concorrencia para uma estrada de ferro, da estação de S. Bernardo á Colonia do Rio Grande. Diário Oficial do Estado de São Paulo, Actus do Poder Legislativo, São Paulo, 5 de dezembro de 1896. Disponível em: http://dobuscadireta.imprensaoficial.com.br/default.aspx?DataPublicacao=18961205 \&Caderno=Diario\%20Oficial\&NumeroPagina=16829. Acesso em: 17 ago. 2020.

ZENHA, Celeste. As práticas da justiça no cotidiano da pobreza. Revista Brasileira de História, v. 5, n. 10, p. 123-146, mar./ago. 1985. 